Pacific Journal of Mathematics

COMMENTS ON THE PRECEDING PAPER BY HERZOG AND 


\title{
COMMENTS ON THE PRECEDING PAPER BY HERZOG AND PIRANIAN
}

\author{
P. C. Rosen BLoOM
}

1. Our main purpose here is to extract and formulate explicitly the general principle underlying the construction of Herzog and Piranian. The results in this note are implicitly contained in the computations on pp. 535 and 537 of their paper, and the full credit belongs to them.

2. We use the notation $M(r, f)=\max |f(z)|$ on $|z|=r$.

THEOREM 1. Let $f_{n}$ be analytic in $|z| \leq 1$, let $r_{n}$ be increasing, $0<r_{n} \rightarrow 1$ as $n \rightarrow \infty$, let $a_{n}>0$,

$$
A=\sum_{n=1}^{\infty} a_{n}<+\infty
$$

let $R(t)=\sum a_{k}$ over all $k$ such that $r_{k} \geq t$, and let $g=\sum_{n=1}^{\infty} f_{n}$. If

(a) $M\left(r_{n}, f_{n+1}\right) \leq a_{n}$

and

(b) $\quad M\left(1, f_{n}^{\prime}\right) \leq a_{n}\left(1-r_{n}\right)^{-1}$

for all $n$, then $g$ is analytic in $|z|<1$, and for $|z| \leq 1, r_{n-1} \leq r \leq r_{n}$, we have

$$
\left|g(r z)-\sum_{1}^{n-1} f_{k}(z)-f_{n}(r z)\right| \leq A(1-r)^{1 / 2}+R\left(1-(1-r)^{1 / 2}\right),
$$

$$
\begin{aligned}
\left|g\left(r_{n} z\right)-g\left(r_{n-1} z\right)-f_{n}(z)\right| \leq 2 A & \left(1-r_{n-1}\right)^{1 / 2} \\
& +2 R\left(1-\left(1-r_{n-1}\right)^{1 / 2}\right)+R\left(r_{n}\right) .
\end{aligned}
$$

Proof. We have

Received April 26, 1954.

Pacific J. Math. 4 (1954), 539-543 


$$
\begin{aligned}
\left|f_{k}(r z)-f_{k}(z)\right| & \leq a_{k}(1-r) /\left(1-r_{k}\right) \\
& \leq \begin{cases}a_{k}(1-r)^{1 / 2} & \text { if } r_{k} \leq 1-(1-r)^{1 / 2} \\
a_{k} & \text { if } k \leq n-1,\end{cases}
\end{aligned}
$$

and $\left|f_{k}(r z)\right| \leq a_{k-1}$ for $k>n$. Inequality (1) now follows from

$$
g(r z)-\sum_{k=1}^{n-1} f_{k}(z)-f_{n}(r z)=\sum_{k=1}^{n-1}\left(f_{k}(r z)-f_{k}(z)\right)+\sum_{k=n+1}^{\infty} f_{k}(r z) .
$$

We now apply (1) with $r=r_{n}$ and $r=r_{n-1}$ to estimate

$$
h(z)=g\left(r_{n} z\right)-g\left(r_{n-1} z\right)-f_{n}\left(r_{n} z\right)+f_{n}\left(r_{n-1} z\right)
$$

and obtain (2) from

$$
g\left(r_{n} z\right)-g\left(r_{n-1} z\right)-f_{n}(z)=h(z)-f_{n}\left(r_{n-1} z\right)+\left(f_{n}\left(r_{n} z\right)-f_{n}(z)\right) .
$$

3. We denote by $E(g)$ the set of radial continuity of $g$.

CoR OLLARY la. If $\left|z_{0}\right|=1, \lim \sup _{n \rightarrow \infty}\left|f_{n}\left(z_{0}\right)\right|>0$, then $z_{0} \notin E(g)$.

CorollaRy $1 \mathrm{~b}$. If $\left|z_{0}\right|=1$, and $\lim f_{n}\left(r z_{0}\right)$ exists as $r \rightarrow 1$ and $n \rightarrow \infty$ simultaneously, ${ }^{1}$ then

$$
\lim _{r \rightarrow \infty} g\left(r z_{0}\right) \text { and } \sum_{n=1}^{\infty} f_{n}\left(z_{0}\right)=g\left(z_{0}\right)
$$

either both exist or both do not exist. If $\lim f_{n}\left(r z_{0}\right)=0$, then

$$
\lim _{r \rightarrow 1} g\left(r z_{0}\right)=g\left(z_{0}\right)
$$

if either exists. Hence if $M\left(1, f_{n}\right) \longrightarrow 0$ as $n \longrightarrow \infty$, then $E(g)$ is the set of convergence of $\sum_{n=1}^{\infty} f_{n}(z)$ on $|z|=1$.

\section{We now establish:}

${ }^{1}$ The weaker condition that $f_{n}\left(r z_{0}\right)$ has a limit as $n \longrightarrow+\infty$ and $r \longrightarrow 1$ in such a way that $r_{n-1} \leq r \leq r_{n}$ for all $n$ is sufficient for this corollary. 
THE OREM 2. If $F_{n}$ is analytic in $|z| \leq 1, M\left(1, F_{n}\right) \leq M_{n}, M\left(1, F_{n}^{\prime}\right) \leq M_{n}$ for all $n$, and $a_{n}>0($ all $n), \sum_{n=1}^{\infty} a_{n}<+\infty$, then there exist sequences $r_{n}$ and $k_{n}$ such that $f_{n}(z)=z^{k_{n}} F_{n}(z)$ satisfies $(\mathrm{a})$ and $(\mathrm{b})$ of Theorem 1 .

Proof. Let $k_{1}=0$ and suppose that $k_{2}, \ldots, k_{n}, r_{1}, \ldots, r_{n-1}$ are defined. Then $(b)$ is satisfied if

$$
r_{n} \geq 1-\frac{a_{n}}{M_{n}\left(k_{n}+1\right)}
$$

Choose any $r_{n}$ such that

$$
1>r_{n}>\max \left[r_{n-1}, 1-\frac{a_{n}}{M_{n}\left(k_{n}+1\right)}\right] \text {. }
$$

Then (a) is satisfied if

$$
k_{n+1} \geq \frac{\log \left(a_{n} / M_{n+1}\right)}{\log r_{n}} .
$$

5. As a consequence, we have:

Corollary 2a. If

$$
\begin{gathered}
\limsup _{n \rightarrow \infty}\left|\alpha_{n}\right|>0, \underset{n \rightarrow \infty}{\limsup } k_{n}^{-1} \log \left|\alpha_{n}\right|=0, \\
a_{n}>0, \sum a_{n}<+\infty, \text { and } \frac{k_{n}+1}{k_{n}} \geq \frac{\left|\alpha_{n}\right|}{a_{n}} \log \frac{\left|\alpha_{n+1}\right|}{a_{n}}
\end{gathered}
$$

for all $n$, then $E(g)=0$, where $g(z)=\sum \alpha_{n} z^{k_{n}}$.

If $\alpha_{n}=O(1), \lim \sup _{n \rightarrow \infty}\left|\alpha_{n}\right|>0, k_{n}$ increasing, and

$$
\sum \frac{k_{n}}{k_{n+1}} \log \frac{k_{n}+1}{k_{n}}<+\infty
$$

then $E(g)=0$.

Corollary 2b. Suppose that $f$ is analytic in the circle $|z| \leq 1, f(1)=1$, $M\left(1, f^{\prime}\right) \leq 1$, and that $a_{n}>0($ all $n)$, 


$$
\sum_{n=1}^{\infty} a_{n}<+\infty
$$

Let

$$
g(z)=\sum_{n=1}^{\infty} z^{k_{n}} f\left(z e^{-i \theta_{n}}\right)
$$

If

$$
\liminf _{n \rightarrow \infty}\left[\frac{k_{n+1}}{k_{n}}+3 \frac{\log a_{n}}{a_{n}}\right]>0,
$$

then $z=e^{i \theta} \notin E(g)$ if $\left|\theta-\theta_{n}\right| \leq(\pi / 3)-h, 0<h<\pi / 3$, for infinitely many $n$. In particular, $E(g)=0$ if the set $\left\{\theta_{n}\right\}$ is dense in the interval $[0,2 \pi]$.

6. The discussion of $C_{n}(z)$ on pp. 534, 535 of the preceding paper shows that they are constructed essentially in accordance with Theorem 2 above. The gap theorem in Corollary $2 a$ is very crude, and can certainly be improved. The high-indices theorem of Hardy and Littlewood and Tauberian methods (see [2] and [3]) yield much sharper results.

7. The construction on p. 537 of Herzog and Piranian can also be carried out as follows.

LEMMA. If $A$ and $B$ are disjoint closed sets in the plane and $B$ is bounded and has a simply connected compliment, and $\epsilon>0$, then there is a polynomial $P(z)$ such that $|P(z)| \leq \epsilon$ on $B$ and $|P(z)| \geq 1$ on $A$.

Proof. Let $T_{n}(z)$ be the Chebyshev polynomial of degree $n$ for $B$; that is, $T_{n}$ is the polynomial of degree $n$ with highest coefficient 1 whose maximum modulus on $B$ is the least possible. Then $T_{n}(z)^{1 / n} \rightarrow \phi(z)$ in the exterior of $B$, where $\phi(z)$ is the function which maps the exterior of $B$ onto the exterior of a circle $|w|>c$ and whose Taylor expansion at $\infty$ begins thus: $\phi(z)=$ $z+\cdots$. Let $c<C<R$ be such that $|\phi(z)| \geq R+\epsilon$ on $A$. Then there is an $n$ such that

$$
\left|T_{n}(z)\right|^{1 \gamma_{n}} \geq R \text { on } A \text { and }\left|T_{n}(z)\right|^{1 / n} \leq C \text { on } B
$$

If $n$ is chosen such that $\epsilon(R / C)^{n} \geq 1$, then $R^{-n} T_{n}$ is a polynomial with the desired properties. 
There are, of course, many other ways of constructing such a polynomial.

Now in the construction on p. 537, take a convergent double series $\sum a_{k h}$ with $a_{k h}>C$. Choose $A=I_{k h}$ and let $B$ be the sector $z=r e^{i \theta}$ with $0 \leq r \leq 1$ and $\theta$ in the closed interval complimentary to $I_{k h}$ and its two adjacent intervals in $G_{k}$. Let $P_{k h}$ be a polynomial such that $\left|P_{k h}(z)\right| \geq 1$ on $I_{k h}$ and $\left|P_{k h}(z)\right| \leq$ $a_{k h}$ on $B$. Arrange the pairs $(k, h)$ in a sequence by the diagonal process, and apply Theorem 2, then Theorem 1.

8. The polynomials $C_{n}$ used by Herzog and Piranian are of the desired type for the sets $A$ and $B$ considered in the preceding paragraph. They provide a simple explicit construction and enjoy other interesting properties which seem to be useful in a number of problems. The fact that they are small on the whole set $B$ above follows from the following remark which is surely known:

If

$$
f(z)=\sum_{n=0}^{\infty} a_{n} z^{n} \text { and } s_{n}(z)=\sum_{k=0}^{n} a_{k} z^{k}
$$

and $0 \leq r \leq 1,|z| \leq 1$, then $|f(r z)| \leq \sup _{n}\left|s_{n}(z)\right|$.

This is a trivial consequence of the identity $f(r z)=O(1-r) \sum_{0}^{\infty} r^{n} s_{n}(z)$.

\section{References}

1. F. Herzog and G. Piranian, Sets of radial continuity of analytic functions, Pacific J. Math. 4 (1954), 533 - 538.

2. N. Levinson, Gap and density theorems, Amer. Math. Soc. Colloquium Publications, New York, 1940.

3. N. Wiener, A Tauberian gap theorem of Hardy and Littlewood, J. Chinese Math. Soc. 1 (1936), 15. 



\section{PACIFIC JOURNAL OF MATHEMATICS}

\section{EDITORS}

\author{
M.M. SCHIFFER * \\ Stanford University \\ Stanford, California \\ E. HEWITT \\ University of Washington \\ Seattle 5, Washington
}

\section{R.P. DILWORTH}

California Institute of Technology Pasadena 4, California

\section{E. F. BECKENBACH**}

University of California

Los Angeles 24, California

\section{ASSOCIATE EDITORS}

$\begin{array}{llll}\text { H. BUSEMANN } & \text { P.R. HALMOS } & \text { BØRGE JESSEN } & \text { J. J. STOKER } \\ \text { HERBERT FEDERER } & \text { HEINZ HOPF } & \text { PAUL LÉVY } & \text { E.G. STRAUS } \\ \text { MARSHALL HALL } & \text { R.D. JAMES } & \text { GEORGE PÓLYA } & \text { KÔSAKU YOSIDA }\end{array}$

\section{SPONSORS}

UNIVERSITY OF BRITISH COLUMBIA

CALIFORNIA INSTITUTE OF TECHNOLOGY

UNIVERSITY OF CALIFORNIA, BERKELEY

UNIVERSITY OF CALIFORNIA, DAVIS

UNIVERSITY OF CALIFORNIA, LOS ANGELES

UNIVERSITY OF CALIFORNIA, SANTA BARBARA

UNIVERSITY OF NEVADA

OREGON STATE COLLEGE

UNIVERSITY OF OREGON
UNIVERSITY OF SOUTHERN CALIFORNIA STANFORD RESEARCH INSTITUTE STANFORD UNIVERSITY WASHINGTON STATE COLLEGE UNIVERSITY OF WASHINGTON

AMERICAN MATHEMATICAL SOCIETY HUGHES AIRCRAFT COMPANY

Mathematical papers intended for publication in the Pacific Journal of Mathematics should be typewritten (double spaced), and the author should keep a complete copy. Manuscripts may be sent to any of the editors. Manuscripts intended for the outgoing editors should be sent to their successors. All other communications to the editors should be addressed to the managing editor, E.G. Straus, at the University of California Los Angeles 24, California.

50 reprints of each article are furnished free of charge; additional copies may be obtained at cost in multiples of 50 .

The Pacific Journal of Mathematics is published quarterly, in March, June, September, and December. The price per volume (4 numbers) is $\$ 12.00$; single issues, $\$ 3.50$; back numbers (Volumes $1,2,3$ ) are available at $\$ 2.50$ per copy. Special price to individual faculty members of supporting institutions and to individual members of the American Mathematical Society: $\$ 4.00$ per volume; single issues, $\$ 1.25$.

Subscriptions, orders for back numbers, and changes of address should be sent to the publishers, University of California Press, ,Berkeley 4, California.

Printed at Ann Arbor, Michigan. Entered as second class matter at the Post Office, Berkeley, California.

* To be succeeded in 1955, by H.L. Royden, Stanford University, Stanford, California.

** To be succeeded in 1955, by E.G. Straus, University of California, Los Angeles 24, Calif.

UNIVERSITY OF CALIFORNIA PRESS - BERKELEY AND LOS ANGELES 


\section{Pacific Journal of Mathematics}

\section{Vol. 4, No. $4 \quad$ August, 1954}

Paul Civin, Orthonormal cyclic groups .................... 481

Kenneth Lloyd Cooke, The rate of increase of real continuous solutions of

algebraic differential-difference equations of the first order ......... 483

Philip J. Davis, Linear functional equations and interpolation series . . . . . 503

F. Herzog and G. Piranian, Sets of radial continuity of analytic functions . . 533

P. C. Rosenbloom, Comments on the preceding paper by Herzog and

Piranian ............................................. 539

Donald G. Higman, Remarks on splitting extensions .............. 545

Margaret Jackson, Transformations of series of the type ${ }_{3} \Psi_{3} \ldots \ldots \ldots \ldots 557$

Herman Rubin and Patrick Colonel Suppes, Transformations of systems of relativistic particle mechanics ....................... 563

A. Seidenberg, On the dimension theory of rings. II .............. 603

Bertram Yood, Difference algebras of linear transformations on a Banach

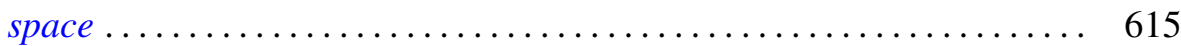

